\title{
ОБЗОРЫ
}

\section{Влияние дискриминации на фондовом рынке на рыночную стоимость компаний в Китае}

\author{
Алексеев А.А. ${ }^{17}$, Иванинский И.О. ${ }^{18}$, Озорнина О.В. ${ }^{19}$, Серебрянский \\ Д.В. ${ }^{20}$, Силаев И.А. ${ }^{21}$
}

В статье рассматривается влияние дискриминаџии на фондовом рынке Китая на рыночную стоимость торгуюшихся на нем компаний. На фондовом рынке Китая существует два типа акций: акции типа А, доступнье для инвесторов-резидентов Китая; и акции типа B, доступные для иностранных инвесторов. Такая структура не является характеристикой исключительно китайского рынка, она принята в таких странах, как Финлядия, Сингапур, Швейщария, Таиланд и др. Однако, в отличие от большинства стран со сходной структурой фондового рынка, на рынке Китая акиии, доступные для иностранных инвесторов, торгуются со значительной скидкой по сравнению с акциями, доступными для инвесторов-резидентов. Столь необычная ситуация объясняется такими факторами, как асимметрия информации между инвесторами резидентами $u$ нерезидентами Китая; разная ликвидность для акций разных типов; эффект диверсификации, появляюшийся у инвесторов при вложении в акичи китайских компаний; размер компании-объекта вложения; соотношение количества акиий разных типов у компании; влияние того, на какой бирже торгуются акции компании.

JEL: G10, G11, G12, G14, G18

Ключевые слова: Китай, фондовый рынок, рыночная дискриминачия, ликвидность, акции с ограничением, сегментация

\section{Введение}

Одним из наиболее актуальных направлений современных прикладных корпоративных финансов является оценка стоимости компаний. Оценка стоимости находит применение в таких областях, как слияния и поглощения, решение судебных вопросов, связанных с деятельностью предприятий, наконец, просто определение эффективности деятельности компании. Одним из популярных стандартов оценки является обоснованная рыночная стоимость.

Строго говоря, это довольно неточный способ определения стоимости. Тем не менее он очень важен в практике. То, как рынок оценивает стоимость компании, позволяет делать выводы об эффективности менеджмента, об инвестиционной привлекательности компании. Кроме того, рыночная стоимость является также индикатором ожиданий относительно компании. Однако для того чтобы перечисленные выше положительные стороны данного метода оценки были реализованы, необходимо, чтобы выполнялся ряд предпосылок:

\footnotetext{
${ }_{17}^{17}$ Стажер-исследователь научно-учебной Лаборатории корпоративных финансов ГУ-ВШЭ

${ }^{18}$ Стажер-исследователь научно-учебной Лаборатории корпоративных финансов ГУ-ВШЭ

19 Стажер-исследователь научно-учебной Лаборатории корпоративных финансов ГУ-ВШЭ

${ }^{20}$ Стажер-исследователь научно-учебной Лаборатории корпоративных финансов ГУ-ВШЭ

${ }^{21}$ Стажер-исследователь научно-учебной Лаборатории корпоративных финансов ГУ-ВШЭ
}

Выпуск \#1(9), 2009

(C) Электронный журнал Корпоративные Финансы, 2009 
• типичность оценки, вытекающая из условий, преобладающих на дату оценки;

- состоянию рынка должно быть свойственно определенное постоянство, он не должен быть подвержен мгновенному буму или внезапной панике;

- оплата наличными деньгами.

К этим предпосылкам можно добавить также отсутствие сегментации на рынке, доступность информации и ряд других предположений, которые в совокупности позволяют нам сформулировать следующее утверждение: рыночная оценка является хорошим индикатором стоимости компании в предположении о выполнении гипотезы эффективного рынка.

Однако, как показало большое количество исследований, справедливость гипотезы эффективного рынка по меньшей мере сомнительна. В настоящем обзоре мы рассмотрим один из примеров нарушения предпосылок гипотезы эффективного рынка - сегментацию рынка.

\section{Сегментированный рынок}

Как было отмечено выше, использование рыночной оценки компании в качестве индикатора ее стоимости справедливо только в предположении об эффективности рынка. Одним из важных свойств эффективного рынка является отсутствие сегментации.

Тем не менее многие рынки имеют законодательно закрепленную сегментированную структуру. Как правило, сегментация связана с доступностью акций для инвесторов резидентов и нерезидентов. Такая структура рынка принята, например, в Финлядии, Сингапуре, Китае, Швейцарии, Таиланде, Мексике и других странах. Бэйлей [Bailey et al., 1999] приводят подробное описание 11 сегментированных рынков с видами сегментации, принятыми на них. Сегментация рынка приводит к тому, что акции, доступные для разных видов инвесторов, торгуются по разным ценам и приносят разную доходность. Следствием этого является невозможность использования рыночной цены компании в качестве показателя ее стоимости, так как непонятно, что является настоящей стоимостью - оценка инвесторами-резидентами или нерезидентами. Тем не менее выяснение механизмов, приводящих к разнице в ценах, позволило бы найти способы решения этой проблемы.

Настоящий обзор посвящен литературе, связанной с последствиями сегментации на фондовом рынке Китая. Китайский фондовый рынок появился сравнительно недавно - в 1990 году - и состоит из двух фондовых бирж - Шанхайской и Шеньженской. Рынок развивался бурными темпами, и к 2008 году суммарная капитализация двух фондовых бирж составляла \$5,899 трлн. К продаже на бирже разрешена только часть выпущенных акций. Неторгуемые акции находятся в собственности правительства, компаний-эмитентов, а также менеджмента этих компаний. Торгуемые акции разделены на два класса - А и В. Акции класса А предназначены для инвесторов-резидентов Китая — кроме резидентов Гонкога и провинции Макао, занимающих особое положение в экономике и политике Китая. Эти акции номинируются и торгуются в юанях. Акции типа В могут приобретаться только нерезидентами и жителями Гонкога и Макао. Акции данного типа также номинированы в юанях, но торгуются в гонконгских или американских долларах, в зависимости от биржи.

Фондовый рынок Китая интересует нас по двум причинам. Во-первых, он так же молод, как и российский рынок; а во-вторых, на нем наблюдается нетипичная для похожих рынков ситуация: в отличие от большинства сегментированных рынков, на фондовом рынке Китая акции, доступные для иностранных инвесторов, торгуются со скидкой по отношению к акциям, доступным для инвесторов-резидентов.

\section{Обзор литературы}

Мы уже говорили, что фондовый рынок Китая не является единственным, на котором введена законодательно закрепленная сегментация. Исследованию последствий сегментации 
на рынках посвящено большое количество работ. Среди наиболее известных можно выделить уже упоминавшуюся выше работу Бэйлей [Bailey et al., 1999], в которой авторы рассматривают 11 сегментированных рынков. Среди более узких исследований, посвященных последствиям сегментации на отдельных рынках, можно выделить Хиеталла [Hietala, 1989] - Финляндия, Лам и Пак [Lam and Pak, 1993] - Сингапур, Бэйлей и Яктиани [Bailey и Jagtiani, 1994] — Таиланд, Стульц и Вассерфален [Stulz and Wasserfallen, 1995] - Швейцария, Домовитц [Domowitz и др., 1997] - Мексика. Все эти исследования показывают, что акции, доступные для иностранцев, торгуются с премией по отношению к акциям, доступным только для резидентов.

Единственным исключением из этого правила является Китай, где акции для инвесторов-нерезидентов торгуются со значительной скидкой по сравнению с такими же аналогами для резидентов. Было предпринято довольно много попыток объяснить причины такого положения, среди них можно выделить Бэйлей [Bailey, 1994], Мa [Ma, 1996], Хакраварти [Chakravarty et al., 1998], Чуй и Квок [Chui and Kwok, 1998], Cy [Su, 1999], Фунг [Fung et al., 2000], Сан и Тонг [Sun and Tong, 2000], Чен [Chen et al., 2001], [Chan et al., 2002], Фернальд и Роджерс [Fernald and Rogers, 2002], Кароли и Ли [Karolyi and Li, 2003]. Ниже мы приводим причины, традиционно выделяемые исследователями как объясняющие скидку на акции типа В, а также прокси, используемые для количественного описания выделяемых причин.

1. Асимметрия информации. Предполагается, что иностранных инвесторов может отпугивать недостаток информации о китайских компаниях, так как рынок Китая очень молод и у инвесторов отсутствует опыт работы на нем. Для описания данной причины традиционно используются следующие прокси-переменные:

a) Отношение ковариации доходностей акций типов А и В к дисперсии акций типа А. Использование данного прокси основано на предположении, что иностранные инвесторы оценивают перспективы доходностей акций типа В исходя из того, насколько они связаны с доходностями акций типа А. Предполагается, что локальные инвесторы обладают информацией, недоступной для иностранных инвесторов.

б) Волатильность акций типа В. Считается, что чем более волатильны акции типа В, тем сложнее иностранным инвесторам делать прогнозы относительно их цен и тем больше скидка.

в) Частота упоминания компании в прессе. Считается, что чем чаще компания, акции которой торгуются на бирже, упоминается в прессе, тем меньше асимметрия информации и тем меньше должна быть скидка за акции типа В.

В таблице ниже представлены описанные выше факторы и их влияние на скидку на акции типа В.

Таблица 1.

Влияние информационной асимметрии на скидку

\begin{tabular}{|c|c|c|}
\hline Переменная & Вычисление & $\begin{array}{l}\text { Влияние } \\
\text { на скидку }\end{array}$ \\
\hline $\begin{array}{l}\text { Чувствительность } \\
\text { доходностей акций типа В }\end{array}$ & $\begin{array}{l}\text { Ковариация доходностей акций } \\
\text { А и В, разделенная на } \\
\text { коэффициент вариации цены } \\
\text { акций типа A }\end{array}$ & - \\
\hline $\begin{array}{l}\text { Коэффициент вариации акций } \\
\text { типа В }\end{array}$ & $\begin{array}{l}\text { Коэффициент вариации } \text { акций } \\
\text { типа В }\end{array}$ & + \\
\hline $\begin{array}{l}\text { Информационное } \\
\text { компании }\end{array}$ & $\begin{array}{l}\text { Количество у упоминаний } \\
\text { компании в прессе }\end{array}$ & - \\
\hline
\end{tabular}


2. Ликвидность. В том случае, если на закрытие позиции необходимы дополнительные время и затраты, инвесторы будут требовать за это скидку. Для оценки ликвидности и ее влияния на скидку используются два прокси:

a) Отношения объемов торгов по акциям типа В и типа А. Чем больше этот показатель, тем больше относительная ликвидность акций типа В.

б) Отношения bid-ask спредов по акциям двух типов. Bid-ask спред, являясь индикатором ликвидности акции, позволяет судить о том, насколько предложение превышает спрос и каковы потери инвестора в случае потребности в немедленной продаже акций. Чем меньше спред, тем более ликвидна акция и тем меньше требуемая скидка.

В таблице ниже представлены описанные выше факторы и их влияние на скидку на акции типа В.

Таблица 2.

Влияние ликвидности на скидку

\begin{tabular}{|l|l|l|}
\hline \multicolumn{1}{|c|}{ Переменная } & \multicolumn{1}{|c|}{ Вычисление } & \multicolumn{1}{|c|}{$\begin{array}{c}\text { Влияние } \\
\text { на скидку }\end{array}$} \\
\hline Относительный спред & $\begin{array}{l}\text { Отношение bid-ask спредов по акциям } \\
\text { А и В разделенных на цены } \\
\text { соответствующих акций }\end{array}$ & + \\
\hline $\begin{array}{l}\text { Относительный объем } \\
\text { торгов }\end{array}$ & $\begin{array}{l}\text { Отношение объемов торгов по акциям } \\
\text { разных типов }\end{array}$ & - \\
\hline
\end{tabular}

3. Диверсификационные выгоды. В том случае, если включение акции в портфель приводит к диверсификации, это должно положительно влиять на ценность данной акции для инвестора. Так, для инвестора-нерезидента Китая включение в портфель акций типа В может приводить к диверсификации. Для оценки того, так ли это, в литературе традиционно используется коэффициент корреляции между доходностью акции и доходностью рыночного портфеля. В качестве рыночного портфеля традиционно рассматривается индекс фондового рынка. В зависимости от рассматриваемого инвестора, индекс может быть как локальным (например, в случае с Китаем - Shanghai Composite), так и глобальным (таким, как S\&P 500). Однако независимо от индекса корреляция доходностей акции и индекса положительно связана с размером скидки за акцию.

4. Размер компании. Предполагается, что инвесторам проще собирать информацию о крупных компаниях, чем о маленьких. Таким образом, размер отрицательно влияет на величину скидки.

5. Относительный объем предложения акций типа А. Относительно большее количество предложенных к продаже акций типа А должно оказать негативное влияние на их стоимость, таким образом сократив размер скидки на акции типа В.

6. Влияние биржи. С технической точки зрения обе биржи Китая ничем не различаются. Тем не менее ряд исследователей, в частности уже отмеченные выше Хакраварти [Chakravarty et al., 1998], отмечают предвзятое отношение к Шанхайской бирже. Если акции торгуются на ней, то скидка возрастает. Для описания этого влияния используется дамми-переменная.

В таблице ниже представлены влияния описанных факторов на скидку. 
Таблица 3.

Влияние на скидку разных параметров

\begin{tabular}{|l|l|l|}
\hline \multicolumn{1}{|c|}{ Переменная } & \multicolumn{1}{|c|}{ Вычисление } & \multicolumn{1}{c|}{$\begin{array}{c}\text { Влияние на } \\
\text { скидку }\end{array}$} \\
\hline Размер & Логарифм продаж & - \\
\hline $\begin{array}{l}\text { Отношение количества } \\
\text { торгуемых акций типа A к } \\
\text { типу В }\end{array}$ & $\begin{array}{l}\text { Отношение коргуемых акций типа А к } \\
\text { типу В }\end{array}$ & - \\
\hline Биржевая площадка & $\begin{array}{l}\text { Дамми равна 1, если биржа } \\
\text { Шанхайская }\end{array}$ & + \\
\hline
\end{tabular}

Особо выделим дополнительные параметры, которые сложно вставить в описанные модели, но которые оказывают сильное влияние на конечные результаты.

Различие в налоговом законодательстве может объяснить различие в полученных результатах исследования. В работе Домовитц, Глен и Мадхаван [Domowitz, Glen and Madhavan, 1997] показано, что малое значение премии для акции инвесторов-резидентов частично вызвано высокими налоговыми ставками на доход от дивидендов и продажи акций конечными держателями. Однако данное объяснение плохо подходит для большинства развивающихся стран, таких как Малайзия, Филиппины, Сингапур, Таиланд, где либо отсутствует налогообложение сделок по продаже, либо налоговая ставка незначительна.

Интересным вопросом, поднятым в статье Бэйлей [Bailey, 1999], является наличие альтернативных методов доступа иностранных инвесторов на локальный рынок. Домовитц, Глен и Мадхаван [Domowitz, Glen and Madhavan, 1997] приводят примеры траст-фондов в Мексике. Подобного рода неявные схемы трудно описать и проанализировать, но точно нельзя исключать из рассмотрения.

Результаты, полученные для данных рынка Китая, плохо поддаются объяснению. Нельзя ответить однозначно, почему инвесторы-резиденты платят больше за активы, в отличие от иностранных коллег. В работе Бэйлей [Bailey, 1994] предполагается, что местные китайские банки из-за нехватки альтернатив для инвестирования подняли цены на местные активы. Из-за нехватки данных данное предположение не было проверено.

Альтернативное объяснение было предложено Сан и Тонг [Sun and Tong, 2000]. Авторы нашли объяснение скидке на акции типа В. Спрос на данный тип акций является более эластичным по сравнению со спросом на акции типа А, так как у инвесторов существует субститут - акции, торгуемые на бирже в Гонконге, что было отмечено в предыдущих исследованиях. Авторы настоящей статьи выдвигают гипотезу, что эффективными субститутами являются также китайские акции, торгуемые на американской бирже, и эта гипотеза подтвердилась после проведения регрессионного анализа. Кроме того, в статье было подтверждено существование найденной ранее закономерности, согласно которой, количество и стоимость китайских акций, торгуемых на бирже Гонконга, отрицательно связаны с премией на В-акции. Интересной дополнительной информацией является проведенное эмпирическое исследование скидок после вступления в силу 19 февраля 2001 года изменения законодательства, согласно которому, внутренние инвесторы также могут инвестировать в акции типа В. Сан и Тонг в данном исследовании обнаружили, что средняя скидка сократилась с 79,77 до 44,97\% после изменения в регулировании. Далее были рассчитаны ежеквартальные скидки с 2002-го по 2004 года. На их основании было выявлено, что с течением времени скидки сохраняются на уровне, установившемся после введения новых правил на торговлю В-акциями, и теперь составляют около 45\%. Следовательно, размер скидки определяется эндогенными факторами, природу которых 
следует изучить в дальнейших работах.

\section{Список литературы}

1. Bailey, W, Chung, Y. P and Kang, J. (1999), Foreign Ownership Restrictions and Equity Price Premiums: What Drives he Demand for Cross-Border Investments? Journal of financial and quantitative analysis (1999).

2. Bailey, W. (1994), Risk and Return on China's New Stock Markets: Some Preliminary Evidence, Pacific Basin Finance Journal, 2 (May 1994) 243-260.

3. Choe, H., Kho, B.-C. and Stulz, R. M. (1998), Do Foreign Investors Destabilize Stock Markets? The Korean Experience in 1997. Unpubl. Working Paper, Ohio State Univ. (1998) forthcoming.

4. Domowitz, I., Glen, J. and Madhavan, A. (1997), Market Segmentation and Stock Prices: Evidence rom an Emerging Market, Journal of Finance, 52 (July 1997) 1059-1086.

5. Errunza, V. and Losq, E. (1985), International asset pricing under mild segmentation: Theory and test, Journal of Finance, 40 (1985) 105-124.

6. Henry, P. B. (2000), Stock Market Liberalization, Economic Reform, and Emerging Market Equity Prices, The Journal Of Finance, Vol. Lv, 2 (April 2000).

7. Stapleton, R. and Subrahmanyam, M. (1977), Market imperfections, capital market equilibrium, and corporate finance, Journal of Finance 32 (1997) 307-319.

8. Stulz, R. M. (1999a), International portfolio flows and security markets, Working paper, Dice Center for Financial Economics, The Ohio State University.

9. Stulz, R. M. (1999b), Globalization and the cost of equity capital, Working paper, The New York Stock Exchange. 